\title{
Silêncio organizacional: introdução e crítica
}

\author{
Organizational Silence: introduction and critique
}

\author{
Marcos Júnior de Moura-Paula ${ }^{1}$ \\ Universidade Federal de Minas Gerais, Centro de Pós-Graduação e Pesquisas em Administração, Belo Horizonte - MG, Brasil \\ Deise Luiza da Silva Ferraz ${ }^{2}$ \\ Universidade Federal de Minas Gerais, Departamento de Ciências Administrativas, Centro de Pós-Graduação e Pesquisas em \\ Administração, Belo Horizonte - MG, Brasil
}

\begin{abstract}
Resumo
Com as mudanças ocorridas a partir dos anos 1970, as organizações passaram a requerer maior participação de seus trabalhadores nos processos de trabalho. A comunicação franca e aberta torna-se vital nesse cenário. $O$ silêncio organizacional (MORRISON e MILLIKEN, 2000) e o silêncio dos empregados (PINDER e HARLOS, 2001) passam a ser estudados com mais profundidade para se compreender os comportamentos que levam os empregados a se valerem da voz, via relato (speaking up), ou permanecerem em silêncio. Desde os anos 2000, o silêncio tem ganhado interesse crescente de pesquisa (BRINSFIELD, EDWARDS e GREENBERG, 2009), sendo que, neste ensaio, o objetivo é apresentar e inserir o silêncio organizacional na agenda de pesquisa sobre Comportamento Organizacional no Brasil. Para tanto, apresentamos o que a literatura estrangeira trata como motivos que levam os empregados a permanecerem em silêncio e quais as consequências desse silêncio tanto para eles quanto para a organização. Acreditamos, contudo, que há limitações nas reflexões desenvolvidas. Para não incorrermos em uma importação domesticada de saberes, apresentamos algumas reflexões, ainda incipientes sobre o tema, a partir de debates desenvolvidos por estudiosos brasileiros (especialmente, TRAGTENBERG, 1971; 2005; PRESTES MOTTA, 1981; PAES DE PAULA, 2002; FARIA e MENEGHETTI, 2011) sobre o caráter ideológico e, portanto, opressor dos conhecimentos produzidos nas ciências administrativas. Criticamos, assim, alguns dos pressupostos da teoria sobre o silêncio organizacional, chamando atenção para a própria organização como fomentadora do silêncio e das consequências que dele podem surgir.
\end{abstract}

Palavra-chave: Abordagem Crítica. Silêncio Organizacional. Silêncio dos Empregados.

\begin{abstract}
With the changes that happened from the 1970s, organizations started to demand more participation of their employees in work processes' decisions. Open and frank communication becomes vital in this scenario. The organizational silence (MORRISON e MILLIKEN, 2000) and the employee silence (PINDER e HARLOS, 2001) are to be studied in more depth to understand the behaviors that lead employees to voice, via speaking up, or to remain silent. Since the 2000s, silence has gained an increasing research interest (BRINSFIELD, EDWARDS e GREENBERG, 2009), and this paper aims to introduce the organizational silence on the research agenda on Organizational Behavior in Brazil. Therefore, we present what the foreign literature points out as motives that lead employees to remain silent, and the consequences of this silence both for them and for the organization. We believe, however, that there are limitations in the reflections developed. To prevent a domesticated introduction of knowledge, we present some still emerging reflections on the subject based on debates by some Brazilian scholars (especially, TRAGTENBERG, 1971; 2005; PRESTES MOTTA,
\end{abstract}

Artigo submetido em 3 de janeiro de 2014 e aceito para publicação em 12 de novembro de 2014.

DOI: http://dx.doi.org/10.1590/1679-395114581

${ }^{1}$ Mestre em Administração pela Universidade Federal de Minas Gerais. Endereço: R. Ita, 42, Saudade, CEP 30285-550, Belo Horizonte - MG, Brasil. E-mail: mourapaula@ufmg.br

${ }^{2}$ Doutora em Administração pela Universidade Federal do Rio Grande do Sul; Professora adjunta do Departamento de Ciências Administrativas e do Centro de Pós-Graduação e Pesquisas em Administração da Faculdade de Ciências Econômicas da UFMG. Endereço: Universidade Federal de Minas Gerais, Av. Antônio Carlos, 6627 - Gabinete 4034 - Pampulha, CEP 31270-901, Belo Horizonte - MG, Brasil. E-mail: deiseluiza@face.ufmg.br 
1981; PAES DE PAULA, 2002; FARIA e MENEGHETTI, 2011) on the ideological character and, therefore, oppressive side of the knowledge produced by management science. So, we criticize some of the underlying assumptions of the organizational silence theory, drawing attention to the role of the organization itself as sponsor of both silence and the consequences that may arise from it.

Keywords: Critical Approach. Organizational silence. Employee silence.

\section{Introdução}

Desde os anos 1970, o mundo, com especial ênfase o Ocidente, vem passando por grandes mudanças. O paradigma de produção fordista cede lugar ao toyotista (PAES DE PAULA, 2002), mais adequado às novas demandas por que passam as empresas, quais sejam: uma concorrência acirrada, consumidores mais atentos e um ambiente altamente mutável (VAKOLA e BOURADAS, 2005). Torna-se necessário rever o posicionamento estratégico, financeiro, de processos, de recursos humanos etc. (FLANNERY, HOFRICHTER e FLATTEN, 1997). Nesse cenário, Beer (1997) indica que a Gestão de Recursos Humanos deve, pois, focar-se mais em questões estratégicas (comprometimento dos empregados com melhoria contínua, maior competência gerencial, comunicação organizacional aberta etc.) do que nas tradicionais (recrutamento, seleção, retenção de talentos etc.). Essa alteração no foco da Gestão de Recursos Humanos não se realizou sem consequências para a força subjetiva do trabalho, o recurso vivo gerido. Podemos destacar, por exemplo, o estresse pelo qual passam os trabalhadores, as modificações na noção de carreira e a intensificação do trabalho por meio da tecnologia.

As novas tecnologias introduzidas pela gestão tanto facilitam o trabalho como também aumentam o controle sobre o trabalhador, podendo ser - e muitas vezes sendo - uma nova fonte de opressão, angústia e exploração (ANTUNES, 1999; FARIA, 2004; PAES DE PAULA, 2002; TONELLI, 2008). A própria noção de carreira fica comprometida, pois a flexibilização pela qual passa o trabalho divide os trabalhadores entre um pequeno grupo central que terá acesso a uma carreira e um grupo periférico maior, que ficará submetido às imprevisibilidades do contexto econômico (CHANLAT, 1996). Ademais, as exigências para progredir na carreira impactam em toda a família, como mostra o estudo de Oltramari (2010). Acrescente a isso que, ao estudar sobre o assédio moral e o burnout, Paiva e Casalechi (2010) identificaram "a tristeza e o desânimo" entre os trabalhadores. Temos, portanto, muitos pesquisadores denunciando as mazelas trazidas pela forma de organização e controle do processo de trabalho. Acrescente-se que temos uma organização sindical que pouco consegue fazer para alterar tais condições de trabalho (ALVES, 2005). Um dos fatores dessa baixa resistência coletiva passa pela não organização dos trabalhadores.

Hodiernamente, os problemas são coletivos, mas, em geral, vivenciados na individualidade. Para superar essa esfera, é necessário que as experiências relacionadas ao trabalho sejam compartilhadas (IASI, 2006; FERRAZ, 2010), que os problemas do quotidiano sejam divididos e os obstáculos à realização da tarefa sejam relatados. A partir dessas informações e de uma observação inicial sobre as relações de trabalho contemporâneas, algumas indagações se impuseram à reflexão: por que os trabalhadores, em geral, não relatam sobre suas condições de trabalho? Ou, ainda, por que silenciam sobre o processo que os torna doentes e/ou lhes causa sofrimento? Segundo Chamberlain (2012), menos de dez por cento dos trabalhadores terceirizados reclamam os direitos que não usufruíram durante a existência do vínculo de trabalho. $\mathrm{O}$ silêncio sobre irregularidades, melhor dizendo, ilegalidades nas relações de trabalho, parece transpor o muro das empresas. Mas, se não recorrem às esferas externas, questionamos se também não há esse silêncio no interior das empresas ou, dito de outra maneira: os trabalhadores relatam questões ligadas ao trabalho para seus supervisores ou outras instâncias na organização? E se relatam, são questões vinculadas à resolução de problemas para melhoria do processo de trabalho ou para a melhoria das condições de trabalho visando reduzir as mazelas relatadas anteriormente?

Consideramos que uma discussão relevante para as possíveis respostas àquelas indagações passa por compreender tanto o discurso organizacional, como o silêncio nas organizações. Na década de 2000, as 
pesquisas em Comportamento Organizacional no Brasil investigaram principalmente: o comprometimento organizacional, o contrato psicológico, a socialização e a identidade nas organizações (SOBRAL e MANSUR, 2013). As poucas pesquisas publicadas sobre silêncio estão preocupadas em analisar o silêncio entre organizações, e entre elas e a sociedade (VIEIRA, CRUBELLATE, SILVA et al., 2002; CARRIERI, SILVA e PIMENTEL, 2009), o silêncio que encobre o assédio moral e sexual no trabalho (FREITAS, 2001) e o silêncio como resistência à mudança organizacional (MAIA e MAIA, 2008). Nenhuma delas, entretanto, teve o silêncio dentro das organizações no que tange à exposição de ideias e de opiniões dos trabalhadores sobre as questões do processo e do ambiente de trabalho como objeto de análise.

Encontramos essas reflexões realizadas por estudiosos não brasileiros e, nesse sentido, o objetivo deste ensaio é propor que o tema Silêncio Organizacional seja introduzido na agenda de pesquisa dos estudos sobre Gestão de Pessoas e Comportamento Organizacional no país. Para atender a esse objetivo, a primeira seção desse texto apresentará o que já foi desenvolvido sobre o tema por pesquisadores americanos, europeus e asiáticos. Contudo, acreditamos que há limitações nas reflexões desenvolvidas. Para não incorrer em uma importação domesticada de saberes, a segunda seção deve apresentar algumas reflexões, ainda incipientes sobre o tema a partir de debates desenvolvidos por estudiosos brasileiros sobre o caráter ideológico e, portanto, opressor das organizações; traremos, sobretudo, as contribuições de Prestes Motta (1981), Tragtenberg (1971; 2005), Faria e Meneghetti (2011) e Paes de Paula (2002). Por fim, este ensaio apresentará algumas questões para futuras pesquisas na sua seção final, que decorreram das colocações das seções que a precederam.

\section{O Silêncio Organizacional: Debates Já Existentes}

Mesmo sendo considerado um fenômeno marcante e onipresente nas organizações (MORRISON e MILLIKEN, 2000; PINDER e HARLOS, 2001; PERLOW e WILLIAMS, 2003), até o início da década de 2000, havia pouca literatura acadêmica sobre o silêncio ${ }^{3}$ (MORRISON e MILLIKEN, 2000; VAN DYNE, ANG e BOTERO, 2003). Em 2003, o Journal of Management Studies (v. 40, n. 6) lançou uma edição especial sobre voz e silêncio nas organizações. Morrison e Milliken (2003) observaram que havia apenas dois artigos teóricos em gestão que se dedicavam ao silêncio nas organizações: Morrison e Milliken (2000), que cunham o termo silêncio organizacional e a noção de climas de silêncio dentro das organizações, analisando o papel da gerência como fomentadora de tais climas; e Pinder e Harlos (2001), que focam nas decisões dos empregados sobre quando relatar (speak up) as injustiças percebidas, sendo o silêncio a retenção de expressões genuínas de certas circunstâncias organizacionais, que as pessoas seriam capazes de modificar caso se comunicassem livremente.

O trabalho de Morrison e Milliken (2000) é uma referência, sendo citado em todos os artigos que tratam sobre o assunto. Pinder e Harlos são também importantes por trabalharem o silêncio como conceito multifacetado; Detert e Edmondson (2011), premiados pelo Academy of Management Journal (2012) pelo melhor artigo de 2011, fazem uma contribuição importante, pois complementam o trabalho de Morrison e Milliken (2000) - focado em nível coletivo - ao se preocuparem em avaliar se os empregados trazem concepções sobre quando devem ou não ficar em silêncio - nível individual.

Morrison e Milliken (2000) criam o conceito de silêncio organizacional, que é a retenção de opiniões e de problemas organizacionais por parte dos empregados. Para as autoras, essa retenção não é um fato individual, embora assim se manifeste, mas um fenômeno coletivo, pois envolve tanto a relação com pares, com os superiores, como também pode ser um desdobramento de um ambiente mais ou menos propício para

3 Brinsfield, Edwards e Greenberg (2009) apontam que o silêncio começa a ser estudado mais profundamente a partir dos anos 2000 , embora alguns trabalhos já o mencionassem anteriormente. Os autores argumentam que Hirschman (1973) é pioneiro no estudo da voz (como resposta à insatisfação e ao declínio) nas organizações, subsumindo o silêncio ao conceito de lealdade. 
o silêncio em função das crenças hegemônicas presentes na cultura organizacional. Pinder e Harlos (2001) indicam que o silêncio dos empregados é um conceito multifacetado que inclui a ausência de discurso ou expressão formal, mas não se limita à ela; o silêncio pode ocorrer mesmo em meio a sons e linguagem. $\mathrm{O}$ silêncio organizacional (nível coletivo) e o silêncio dos empregados (nível individual) são conceitos complementares, mas distintos. Como lembram Brinsfield, Edwards e Greenberg (2009), o que leva um empregado a ficar em silêncio pode evoluir para que um conjunto deles também passe a silenciar.

O silêncio não é necessariamente antônimo de voz (PINDER e HARLOS, 2001; VAN DYNE, ANG e BOTERO, 2003). Para Van Dyne, Ang e Botero (2003), o que diferencia voz e silêncio não é a presença ou a ausência da fala (speak up $)^{4}$, mas sim as motivações para reter em vez de expressar ideias, informações e opiniões que digam respeito a melhorias no trabalho. Assim, a diferença entre voz e silêncio para os autores está relacionada à expressão (voz) ou retenção (silêncio) voluntária de ideias relevantes, opiniões e informações relacionadas ao trabalho.

Para Bowen e Blackmon (2003), o silêncio organizacional ocorre quando as pessoas não podem contribuir livremente para o discurso organizacional. Contudo, romper com esse silêncio somente é possível quando a mensagem tem por objetivo alterar as circunstâncias (avaliadas individual, comportamental ou afetivamente como passíveis de mudança ou retificação) e é direcionada àqueles que podem efetivamente modificá-las; caso contrário, a expressão do pensamento que não seja relatar (speak up) não é entendida como um romper com o silêncio (PINDER e HARLOS, 2001). As organizações buscam, pois, formas de obter os relatos de seus empregados que revelem problemas relacionados ao trabalho, ajudem a solucioná-los e assim, melhorar o desempenho organizacional. Premaux e Bedeian (2003) definem o ato de relatar (speaking up) como declarações abertas de alguém sobre suas opiniões e pontos de vista relacionados ao trabalho, que incluem ou não ações ou ideias de outrem, sugestões ou mudanças necessárias, como também abordagens alternativas ou diferentes linhas de raciocínio sobre o fato/problema comunicado.

Se, por um lado, relatar o que está afetando o trabalho indica o uso da voz pelo empregado, por outro, calarse significa que ele está exercendo seu direito ao silêncio, que, para ele, pode ser mais seguro. Como observam Morrison e Milliken (2003), o silêncio pode ser causado por medo, pelo desejo de não ser o portavoz de más notícias ou ideias indesejáveis, como também por normas ou pressões sociais que há nos grupos. Assim, as pesquisas visam, principalmente, compreender quais fatores levam os empregados a permanecer calados em vez de relatar, ou seja, buscam compreender os fatores que atuam sobre a tensão estabelecida entre calar-relatar. Há tentativas de entender os comportamentos por parte da gerência (MORRISON e MILLIKEN, 2000), essas que fomentam o silêncio, como também os comportamentos por parte dos empregados (DETERT e EDMONDSON, 2011), que tendem a permanecer calados mesmo em organizações nas quais estes não tenham passado por situações de silenciamento.

Outras pesquisas identificam que existem diferentes formas de silêncio, por exemplo, Van Dyne, Ang e Botero (2003), a partir de Morrison e Milliken (2000) e Pinder e Harlos (2001), classificam o silêncio como: aquiescente, isto é, a retenção de ideias relevantes em função de um sentimento de resignação, e defensivo (quiescent), isto é, o silêncio fruto de uma reflexão estratégica sobre as ideias que devem ou não ser retidas. Nesse sentido, os autores introduzem o conceito de silêncio pró-social, que é a retenção de opiniões, informações ou ideias com o intuito de beneficiar outrem ou a própria organização. Wang e Hsieh (2013) consideram os silêncios aquiescente e defensivo disfuncionais para as organizações, pois podem impedir a mudança e suprimir melhorias no desempenho organizacional.

A seguir, são apresentados e sintetizados: os possíveis motivos relacionados ao silêncio dos empregados; as possíveis consequências desse silêncio para os empregados e para as organizações; e prescrições sobre quando se deve optar pelo silêncio. Com essa divisão, busca-se facilitar a visualização de alguns conceitos

\footnotetext{
${ }^{4}$ To speak up significa "falar alto" no sentido de chamar a atenção para algo, o verbo em português que mais se aproxima dessa definição é "vozear". Com exceção dessa primeira ocorrência, nas demais traduziremos speak up como "relatar", pois esse é o significado que nos parece mais coerente com as definições dadas pelos diferentes pesquisadores sobre silêncio aqui citados.
} 
ou observações que ajudam na compreensão do Silêncio nas Organizações e seus efeitos sobre os diferentes atores (indivíduos e organização) envolvidos.

\section{O silêncio entre os empregados}

A relutância dos empregados em relatar problemas, apontada por Bowen e Blackmon (2003), por exemplo, pode estar relacionada ao temor que os gerentes têm em receber feedback negativo e a um conjunto de crenças implícitas que os gerentes têm sobre os empregados (MORRISON e MILLIKEN, 2000). Essa situação pode gerar o que Morrison e Milliken (2000, p. 708) chamam de "clima de silêncio", isto é, uma ideia amplamente divulgada de que relatar questões ou problemas é perigoso ou inútil. Vakola e Bouradas (2005) ampliam o conceito de clima de silêncio para microclima e macroclima de silêncio. O microclima ocorre quando os empregados acreditam que seus supervisores irão puni-los direta ou indiretamente por questionar-lhes as ações ou quando revelam erros. Já o macroclima ocorre quando a alta gerência se torna relutante em compartilhar seus erros, em pedir ajuda a seus pares ou subordinados e admitir que a solução apresentada por outrem pode funcionar melhor.

Se os gerentes agem conforme os pressupostos da Teoria X (os empregados são interesseiros, preocupam-se apenas consigo mesmos e não são dignos de confiança) (McGREGOR, 1960 apud MORRISON e MILLIKEN, 2000), eles agirão implícita ou explicitamente de modo a obstaculizar a comunicação ascendente (MORRISON e MILLIKEN, 2000). Segundo Morrison e Milliken (2000), o mesmo é válido em relação à crença de que a gerência sabe o que e como algo deve ser feito melhor do que os subordinados. As autoras indicam que há também a crença de que unidade, concordância e consenso são sinais de um ambiente saudável e assim, as discordâncias e as dissensões deveriam ser evitadas. Em suma, se os elementos presentes na cultura da organização estiverem pautados na crença de que empregados são interesseiros, de que a direção sabe mais e que a discordância é ruim, serão criadas políticas e estruturas que não facilitarão ou desencorajarão o fluxo ascendente de comunicação (MORRISON e MILLIKEN, 2000).

Se os gerentes têm pré-concepções sobre os empregados (MORRISON e MILLIKEN, 2000), Detert e Edmondson (2011) indicam que os empregados também desenvolvem concepções sobre o uso ou não da voz com fins de autopreservação, isto é, estruturas de conhecimento utilizadas para evitar problemas que podem advir do ato de relatar a superiores (authorities). Essas concepções são aprendidas ao longo da vida pela experiência direta ou pela observação da existência de uma relação de causalidade: relatar-punir, relatarpremiar (DETERT e EDMONDSON, 2011). Mesmo que não vivenciem situações que confirmem suas percepções, os empregados tendem a manter-se em silêncio. Milliken, Morrison, e Hewlin (2003) também explicam que se pode aprender que se deve ficar calado observando os pares e como eles são tratados quando relatam, ou tentam relatar, alguma crítica e são eventualmente tolhidos pelo superior hierárquico. Detert e Edmondson (2011) destacam algumas crenças que levam os empregados a manterem-se em silêncio: ser identificados como alvos de retaliação futura, falta de dados ou soluções para relatar, não sobrepor o chefe, não constranger o chefe em público e consequências negativas para a carreira por terem se expressado.

Além dessa questão de estrutura, políticas e crenças na organização levantadas por Morrison e Milliken (2000), Milliken, Morrison e Hewlin (2003) chamam a atenção para o "efeito mudo" (MUM Effect $)^{5}$, isto é, uma relutância geral por parte das pessoas de serem os mensageiros que desvelam más notícias. A relação hierárquica entre superior-subordinado parece intensificar esse efeito, pois membros com status inferior no grupo podem sofrer restrições para comunicar-se livremente (MILLIKEN, MORRISON e HEWLIN, 2003).

O temor de ser rotulado como "encrenqueiro" (troublemaker) pode também ser problemático, pois pode inviabilizar a relação do empregado com os colegas; qualquer crítica que ele faça pode ser simplesmente

\footnotetext{
5 "MUM" na verdade é tanto um adjetivo ("calado", "mudo") quanto um acrônimo para "keeping mum about undesirable messages" (ROSEN e TESSER, 1970). A primeira leitura do termo em Milliken, Morrison e Hewlin (2003) nos evocou a imagem de uma múmia, motivo que nos levou a escolher essa tradução para o termo em uma versão anterior deste trabalho. Optamos, agora, por traduzi-lo "mum" como "mudo", mantendo, assim, mais proximidade tanto com o significado do acrônimo quanto com o do próprio termo.
} 
desacreditada por conta do rótulo que recebeu, pode haver consequências negativas para sua vida profissional e, por fim, essa situação pode levá-lo a sair da organização (MILLIKEN, MORRISON e HEWLIN, 2003; VAKOLA e BOURADAS, 2005).

\section{Consequências do silêncio para os empregados}

De acordo com Perlow e Williams (2003), o silêncio pode mesmo destruir equipes de trabalho. Isso ocorre devido ao fato de uma discussão mal resolvida com o superior hierárquico ser rapidamente compartilhada com alguns pares, que podem passar a ver que a organização não está disposta a ouvi-los. Escolher ficar em silêncio não seria uma solução, apenas empurraria a sujeira para debaixo do tapete, pois cada vez que alguém se cala, essa pessoa se submete a uma série de emoções negativas como ansiedade, raiva ou ressentimento (PERLOW e WILLIAMS, 2003).

Premeaux e Bedeian (2003) consideram que há dois tipos de custo quando se decide relatar: os diretos, como tempo e energia para transmitir de modo inteligível o que se está pensando; os indiretos, como risco à imagem, retaliação potencial por parte daqueles com pontos de vista distintos, risco de gerar relações antagônicas e risco à psique (wounded psyche) caso um ponto de vista seja desprezado ou ignorado. Morrison e Milliken (2000) indicam que a tendência que as organizações têm de desencorajar as opiniões dos empregados e seu feedback pode não só comprometer a tomada de decisão organizacional, como também provocar reações indesejadas nos empregados. Para as autoras, o silêncio organizacional pode ensejar três consequências destrutivas: os empregados sentem que não são valorizados; sentem que não têm controle algum sobre o que fazem; e passam a ter alto nível de dissonância cognitiva.

Caso os empregados sintam que as organizações não os valorizam, é menos provável que eles valorizem, confiem ou se identifiquem com a organização. Tal sentimento pode ensejar menor comprometimento, satisfação e motivação interna, e retirada psicológica (MATHIEU e ZAJAC apud MORRISON e MILLIKEN, 2000). Segundo Morrison e Milliken (2000), as pessoas sentem necessidade de ter controle sobre seu ambiente imediato e sobre as decisões que o afetam. Opinar sobre seu trabalho é uma forma de ter parte desse controle; caso não sejam aceitas as opiniões ou críticas, além dos efeitos citados para o sentimento de não valorização, os empregados podem mesmo fazer sabotagens ao trabalho como forma de ter algum controle sobre o que fazem.

Por fim, o silêncio organizacional pode ensejar em dissonância cognitiva, isto é, um estado de aversão que surge quando há uma discrepância entre as crenças de alguém e seu comportamento (FESTINGER, 1957 apud MORRISON e MILLIKEN, 2000). Morrison e Milliken (2000) explicam que o estado de dissonância pode ser superado, modificando as crenças ou os comportamentos de quem os esteja experimentando. Quando não há possibilidade de relatar as situações conflitantes que percebem, a dissonância não pode ser quebrada, sendo possível levar os empregados a ficarem ansiosos e estressados (MORRISON e MILLIKEN, 2000).

\section{Consequências do silêncio para a organização}

Perlow e Williams (2003) indicam que à medida que alguém tenta relatar um problema a seu superior hierárquico e é tolhido (sem uma justificativa clara para não acatar sua crítica), ele compartilha com seus pares o ocorrido. Com o passar do tempo, eles podem entender que a organização não lhes ouve e decidem não compartilhar nenhuma de suas preocupações ou questionamentos. Acrescente-se a isso que a interrupção do fluxo de informações pode comprometer a capacidade de a organização detectar erros e aprender com sua solução (MILLIKEN, MORRISON e HEWLIN, 2003), além da possível perda de empregados pelo aumento da rotatividade (MATHIEU e ZAJAC apud MORRISON e MILLIKEN, 2000), obstaculizando, assim, a aprendizagem nas organizações.

No que toca à relação entre comunicação e aprendizagem organizacional, Schilling e Kluge (2009) destacam o silêncio organizacional como um fator obstaculizador. Bastos, Gondim e Loiola (2004) mencionam que 
não há consenso sobre o que define uma organização que aprende, e acrescentam que, sob o ponto de vista cognitivo/comportamental, pode-se definir as organizações que aprendem "como aquelas capazes de adquirir, criar, produzir novos insights, transferir conhecimentos e modificar o comportamento de seus membros" (GARVIM, 1993 apud BASTOS, GONDIM e LOIOLA, 2004, p. 225). Esse processo, por implicar em mudanças, pode trazer consigo resistências, resultando no que Argyris (1982 apud BASTOS, GONDIM e LOIOLA, 2004) denomina "incompetência hábil", isto é, um comportamento organizacional que evita o conflito e, por consequência, limita o processo de aprendizagem. Essa incompetência hábil manifestase por meio de determinados comportamentos, dentre os quais se destacam: evitar dizer o que se pensa, ter baixa tolerância a conversas francas, evitar situações embaraçosas, dentre outros. Essas formas de resistências são também formas de obstáculos ao processo de compartilhar conhecimentos, mais especificamente, a transferência de conhecimento tácito. Buoro (2005), por sua vez, destaca que, estando o acesso à informação vinculado aos níveis hierárquicos, a comunicação se apresenta como um fator que dificulta o compartilhamento do conhecimento nas organizações.

Morrison e Milliken (2000), Milliken, Morrison e Hewlin (2003) e Blackman e Sadler-Smith (2009) também chamaram a atenção para o fato de o silêncio organizacional impedir a transferência de conhecimento na organização. De acordo com Brinsfield, Edwards e Greenberg (2009), o que diferencia a aprendizagem individual da organizacional não é apenas o conhecimento per se, mas também o método como o conhecimento é armazenado e comunicado aos outros. Percebemos, portanto, que a necessidade de compartilhar conhecimento nas organizações impõe aos estudiosos da gestão do conhecimento e da aprendizagem organizacional a investigação sobre um ato por muito tempo negligenciado: o silêncio.

O silêncio organizacional também compromete a tomada de decisões estratégicas, pois impede que múltiplos pontos de vista sejam apresentados, já que não se permite que os empregados desviem de um pensamento ou ideologia dominante na organização (MORRISON e MILLIKEN, 2000). Quando se bloqueiam os feedbacks negativos, possivelmente se diminui a efetividade organizacional, pois a organização diminui sua habilidade de detectar e corrigir erros (MORRISON e MILLIKEN, 2000), além das dificuldades para que ocorra a mudança organizacional e os efeitos negativos para o desempenho da organização (WANG e HSIEH, 2013). Em suma, embora as decisões estratégicas sejam atos racionais efetuados por membros da cúpula da administração visando atender os objetivos dos acionistas, os teóricos alertam sobre a importância de considerar informações ascendentes, pois elas completam a visão holística necessária para a escolha das opções que se apresentam aos decisores organizacionais. Contudo, não são todas as informações produzidas no quotidiano do trabalho que devem ascender na escala hierárquica, ou seja, há coisas que não devem ser ditas. Sobre isso, discorremos no item a seguir.

\section{Quando e o que não se deve falar}

Perlow e Williams (2003) indicam que o silêncio está associado a virtudes tais como: modéstia, respeito pelos outros, prudência e decoro. Ainda segundo os autores, regras de etiqueta indicam quando as pessoas devem se calar para evitar constrangimentos; há mesmo um provérbio que diz que: "é melhor ficar calado e pensarem que se é um tolo, do que abrir a boca e dar-lhes a certeza". Apesar de haver essa "regra" social, o silêncio nas organizações pode ser, como já mencionado, um entrave ao aprendizado, mudança e tomada de decisões. O desafio seria fazer com que os empregados relatassem mais questões relevantes, sem com isso causar uma sobrecarga de informação (MORRISON e MILLIKEN, 2000).

Milliken e Morrison (2003) afirmam que a organização se tornaria um lugar caótico caso todos se sentissem confortáveis para expressar suas opiniões sobre tudo, havendo, então, uma sobrecarga de inputs que poderiam comprometer a tomada de decisão. Assim, segundo elas, deve-se saber quando o silêncio é funcional, inofensivo (nem disfuncional nem funcional) ou disfuncional, ou seja, não se deve assumir $a$ priori que o silêncio seja sempre negativo (MILLIKEN e MORRISON, 2003). Perlow e Williams (2003) indicam que não se deve discutir questões pequenas, isto é, que não afetariam a qualidade de vida no trabalho ou que seriam esquecidas em uma semana ou um mês. Para os autores, temas devem ser discutidos no tempo certo, seja em relação a prazos de entrega, seja em relação ao estado emocional da pessoa com 
quem se vai argumentar. A indagação que se impõe com essa colocação dos autores é: quem determina qual é o tempo certo para que a organização não se torne um lócus caótico? Faremos algumas reflexões sobre isso na seção que segue.

\section{Algumas Reflexões sobre o Silêncio Organizacional}

Ainda que as teorias aqui apresentadas citem que o silêncio possa ser uma constante na organização, não se toma a própria organização como objeto de análise. Como lembra Prestes Motta (1981, p. 34), "por mais que uma organização se caracterize como aparelho econômico, ela é também aparelho repressivo e aparelho ideológico". Para o autor, "todo aparelho ideológico é repressivo e todo aparelho repressivo é ideológico." (PRESTES MOTTA, 1981, p. 34). As organizações lançam mão do poder disciplinar para conseguir corpos dóceis, "cujo potencial produtivo é liberado e o potencial político inibido." (PRESTES MOTTA, 1981, p. 36). É nesse sentido que o silêncio nas organizações precisa ser debatido, pois a opção por silenciar ou relatar, ou ainda a escolha do momento para ambos os atos, embora, a princípio, pareça ser resultado apenas dos indivíduos sob uma relação de gestor-gerido e suas percepções, uma análise menos parcializada pode revelar o esquema de despolitização dos empregados, decorrência de um sistema opressor.

Observamos a opressão, em seu estado sutil, quando os estudiosos desse tema mencionam que o silêncio somente deve ser quebrado, via relato, quando prejudica os resultados organizacionais, isto é, as questões afeitas ao trabalho somente serão consideradas quando os objetivos dos acionistas estão ameaçados. Ao mesmo tempo, tais pesquisas transmitem a ideia de que a ameaça aos objetivos dos acionistas também são ameaças aos objetivos dos trabalhadores, sejam eles gestores ou seus subordinados, posto que, no entendimento daqueles autores, a organização é uma entidade neutra, que reúne os anseios de todos que em suas atividades estão envolvidos, de modo que, os conflitos, se existirem, são resultado de alguma percepção do gestor e de seu gerido. Contudo, essa postura que entende a organização como um lócus harmônico, cujo desequilíbrio é inserido por características individuais nos leva a indagar: por que os gestores receiam feedbacks negativos? Seria uma característica dos indivíduos que escolhem essa profissão? A partir de reflexões críticas de Tragtenberg (2005) sobre a "psicologização" das relações sociais de trabalho, acreditamos que uma possível resposta a essa questão seria não. Então, seria a situação de mediação que eles ocupam na estrutura organizacional que os coloca sobre a opressão sutil de defender interesses contrários aos interesses daqueles que eles precisam fazer trabalhar? Nessa situação, haveria como obter feedbacks positivos? Essas respostas demandam a realização de reflexões e de pesquisas que estão além do que se propõe neste ensaio. Entretanto, optamos por apontar que uma resposta afirmativa é possível, pois no nível da intersubjetividade, no quotidiano das relações sociais, as características pessoais dos gestores também medeiam a relação de opressão que eles representam. E, além do mais, tanto subordinados como supervisores são sociabilizados para entender que não há contradição entre os interesses desses e do ente organização, de modo que, como aponta Preste Motta:

A organização é sempre boa e irreprovável. Nos casos de conflito, a culpa cai sobre o indivíduo, que freqüentemente entra em depressão. Além disso, a organização é uma construção imaginária, onde a autoridade não está identificada com pessoas, mas com o conjunto da organização. Isto a torna especialmente poderosa e, conseqüentemente, torna o indivíduo muito impotente. [...] Todos esses aspectos, evidentemente, são absolutamente coerentes com a docilidade e a produtividade. (PRESTES MOTTA, 1981, p. 38-9).

Tendo em vista as colocações de Prestes Motta (1981), não são os gerentes que erigem barreiras à comunicação organizacional (MORRISON e MILLIKEN, 2000), mas sim a própria organização burocrática da empresa capitalista moderna enseja tais comportamentos de controle e resposta por parte de superiores e subordinados. Nas organizações modernas os panópticos, de acordo com Teo e Caspersz (2011), são os próprios empregados, colegas de trabalho, pois cada um é, ao mesmo tempo, prisioneiro e guarda, mantendo 
a vigilância sobre o outro constantemente, inclusive mediante a tecnologia (VASCONCELOS, PRESTES MOTTA e PINOCHET, 2003).

Nas organizações empresariais, a burocracia desempenha o papel de mediadora entre os interesses dos proprietários e os dos trabalhadores. Como representantes do corpo burocrático, temos os administradores profissionais: o papel destes é o estabelecimento e a execução das normas que regulam o comportamento dos empregados e preservam os interesses dos acionistas. Em outras palavras, os administradores profissionais incorporam o poder e são os guardiões da "harmonia" na organização: procuram assegurar a produtividade amenizando as naturais tensões entre capital e trabalho, por meio dos instrumentos de controle disponíveis (PAES DE PAULA, 2002, p. 137).

Ainda que as organizações não sejam necessariamente instituições totais, o controle burocrático e vigilância que elas exercem sobre seus empregados permitem comparações. "O controle burocrático das necessidades humanas de grupos relativamente grandes de pessoas nas instituições totais implica algumas consequências importantes". (PRESTES MOTTA, 1981, p. 37). Prestes Motta (1981) destaca que, nas instituições totais, há: um pessoal responsável pela vigilância; distância grande entre internos e dirigentes; dirigentes sentem-se corretos e superiores, internos sentem-se inferiores e culpados; e comunicação restrita entre internos e dirigentes tanto para conversas quanto para a transmissão de informações. A própria vigilância para garantir a produtividade e a busca pela "harmonia administrativa" (TRAGTENBERG, 1974 apud PAES DE PAULA, 2002) impedem que as conversas "francas" ocorram, o que é dito já vai entremeado de silêncio pela própria regulação que faz a organização sobre o que deve ou não ser falado. Quando os pesquisadores indicam que apenas questões relevantes devem ser levantadas, mantém-se a questão repressora sobre o discurso, pois todo relato conterá também o que foi silenciado (ORLANDI, 2007). As teorias administrativas são ideológicas (TRAGTENBERG, 1971) e, portanto, controlar o discurso, que é onde a ideologia se materializa (ORLANDI, 2007), faz-se então necessário. No grupo de internos. podemos colocar tanto as gerências, supervisões e demais trabalhadores, pois quem decide o que será relevante é a cúpula da organização (DUTTON e ASHFORD, 1993), que pode ser considerada como externa. Ao reproduzirem o discurso da cúpula da organização, gerentes e supervisores originam o micro e o macroclima de silêncio, pois engendram as relações de superioridade e correição perante os demais. A posição privilegiada da cúpula dificulta a comunicação, uma vez que ela pode, unilateralmente, dizer o que é ou não digno de ser levado em consideração: ela é a possuidora da comunicação livre na organização.

A divisão entre superior e subordinados e a hierarquia como entraves à comunicação são características da burocracia, pois divisão hierárquica e separação entre os que planejam e os que executam permite que se atinjam os fins almejados (BRESSER-PEREIRA e PRESTES MOTTA, 1986). Portanto, a dinâmica de constituição da burocracia dá-se

[...] com base na divisão do trabalho, que faz com que o trabalhador especializado seja percebido, contraditoriamente, de duas formas: o especialista passa a concentrar conhecimento específico, ao mesmo tempo que destitui dos demais trabalhadores o poder de eles agirem, por falta, justamente, de conhecimentos específicos. (FARIA e MENEGHETTI, 2011, p. 429).

Ainda assim, tanto as organizações quanto os teóricos estão cientes de que os trabalhadores executores podem ter conhecimentos não possuídos pelos especialistas. Torna-se necessário, pois, criar meios que facilitem a comunicação para que esse compartilhamento de conhecimentos ocorra, o que é feito de modo sutil. Sutileza esta que fica clara quando Faria e Meneghetti (2011, p. 429) chamam a atenção para o fato de que:

[...] o trabalhador especializado desumaniza-se cada vez mais, pois o conhecimento, a habilidade ou a competência específica interessam à organização e não ao indivíduo. 
Assim, a organização, que não deve depender de ninguém, articula-se para criar substitutos para o especialista. Criam-se e incentivam-se aparatos ideológicos e um conjunto de tecnologias e técnicas, para envolver o trabalhador de forma sutil e silenciosa. Explicitamse: tecnologia da informação, sistemas de controles gerenciais, manuais de gestão, protocolos de qualidade, normas, regras, hierarquias, assim como técnicas de gestão colaborativas e participativas $[\ldots]$.

O trabalho de Argyris e Schön (1978) é citado por vários pesquisadores (MORRISON e MILLIKEN, 2000; MILLIKEN, MORRISON e HEWLIN, 2003; TANGIRALA e RAMANUJAM, 2008) quando falam da importância da aprendizagem organizacional e das dificuldades que o silêncio impõe. O silêncio também cumpre outro papel, principalmente quando se pensa no jogo do reconhecimento (FARIA, 2004), pois

[...] na organização se pratica o jogo pelo desejo de reconhecimento, em que cada um, desejando ser reconhecido pelo outro, participa do jogo conforme as regras objetivas e as ações subjetivas, manifestas e ocultas. Neste sentido, nem toda palavra pode ser explicitamente dita, embora o seja implicitamente quando repousa sobre o não dito. (FARIA, 2004, p. 128).

Para Orlandi (2007, p. 42), "há silêncios múltiplos: o silêncio das emoções, o místico, o da contemplação, o da introspecção, o da revolta, o da resistência, o da disciplina, o do exercício do poder, o da derrota da vontade etc.". Seria o silêncio, então, apenas uma forma de retenção de informações relevantes? Para Bernardes e Guareschi (2004, p. 90), o silêncio permite que o trabalhador chegue à verdade "sem necessitar do controle do outro, mas de viabilizar a escuta de si mesmo. [...] A prática do silêncio também pode ser relacionada à introspecção, pela qual o sujeito presta atenção a tudo que nele se manifesta".

Dessa forma, o silêncio vai bem além do que apenas reter informações relevantes ao ambiente de trabalho por quaisquer que sejam os motivos. Ele faz parte da própria natureza do sujeito enquanto ser na sua busca pela compreensão de si mesmo e do que se passa a seu redor. Mas o conhecimento produzido pela busca de si, em geral, não interessa às organizações, pois, salvo raras exceções, o objetivo delas não é produzir o autoconhecimento humano, mas sim alcançar resultados financeiros positivos que serão apropriados por um pequeno grupo social, aqueles que estão interessados que "quem" aprenda seja a organização, esse ente que lhes representa abstratamente. É nesses termos que a aprendizagem organizacional é apresentada, como um partilhar de saber que culmina na melhor forma de apropriação do máximo possível de valor produzido sem ter uma correspondência em remuneração, ou seja, um compartilhar que permita um aumento da taxa de mais valia. Desse ponto de vista, faz sentido o consenso que encontramos nos estudos sobre o silêncio organizacional. Embora haja múltiplos entendimentos sobre o que seria esse fenômeno, uma característica está sempre presente, se o que deixar de ser relatado não tiver relação com uma melhoria do desempenho (performance) organizacional, esse calar-se não é silêncio organizacional.

Relevante destacar ainda que, assim como o silêncio organizacional decorre de uma transmutação de interesses contraditórios em interesses comuns por meio da despolitização dos interesses dos trabalhadores, ele também pode ser entendido como um ato político, sobretudo quando ele for um ato de resistência, ou seja, quando não for compreendido apenas como o "não relato" em decorrência do medo de punições. Nesse caso, o silêncio organizacional revela que a ausência do relato está sendo usado como instrumento de luta. Orlandi (2007, p. 29) menciona: "em face de sua dimensão política, o silêncio pode ser considerado tanto parte da retórica da dominação (a da repressão) como de sua contra-partida, a retórica do oprimido (a da resistência)".

Brown e Coupland (2005) trabalham com a ideia de que o discurso na organização pode ser usado como forma de controle e dominação de um grupo sobre os demais, que podem criar estratégias discursivas de resistência perante tal situação. Ainda que as ideologias corporativas sejam poderosas, elas não são absolutas nem impedem que mudanças ocorram (BROWN e COUPLAND, 2005), pois resistência e mudança são não 
apenas possíveis, como ocorrem frequentemente (FAIRCLOUGH, 1989 apud BROWN e COUPLAND, 2005). "Já é bem conhecido que o poder se exerce acompanhado de um certo silêncio (DE CERTEAU, 1980). É o silêncio da opressão." (ORLANDI, 2007, p. 101).

\section{Questionamentos possíveis: o desejo de discussões profícuas na área}

Com base no exposto, acreditamos que, para que as pesquisas sobre silêncio avancem, é necessário que haja variação nos métodos e amostras pesquisados (LEYVA-MORAL, 2007), como também busca por um enfoque menos positivista, que é o que tem pautado as pesquisas (BROWN e COUPLAND, 2005; LEYVAMORAL, 2007). Estudantes de MBA foram a amostra mais frequente nos estudos teórico-empíricos aqui citados, juntamente com organizações com fins lucrativos. As inovações ficaram por conta de novos conceitos, ou aprofundamento teórico de conceitos existentes. Por exemplo, dividir clima de silêncio (MORRISON e MILLIKEN, 2000) em macro e microclima de silêncio (VAKOLA e BOURADAS, 2005), ainda que ajude a compreender o que aquele seja, não explica exatamente como as estruturas organizacionais condicionam tais climas. A forma hegemônica de organização da sociabilidade humana construída historicamente - a burocracia - não é neutra, tampouco o são as teorias administrativas (TRAGTENBERG, 1971). As análises precisam levar também em conta esse aspecto. Caminhar para enriquecer cada vez mais conceitos ligados a determinada corrente (nesse caso, positivista) não contribui para esse intento.

Isso nos leva às seguintes perguntas: por que não se pesquisar também em organizações sem fins lucrativos? Seria possível supor que o conceito de silêncio organizacional de Morrison e Milliken (2000) pudesse ser aplicado a organizações não lucrativas? Há diferenças no silêncio dos empregados em empresas autogeridas e heterogeridas? E quanto às organizações familiares, haveria diferença? Qual a relação entre silêncio e silenciamento organizacional? Do ponto de vista dos trabalhadores, o silêncio organizacional tem o mesmo significado ou eles o entendem de forma distinta da que os pesquisadores têm buscado verificar? $\mathrm{O}$ que significa o silêncio dos trabalhadores frente ao discurso organizacional? O que eles estariam silenciando quando reproduzem um discurso opressor? Se introduzirmos a discussão sobre alienação e emancipação, o conceito silêncio organizacional - como apresentado pelos pesquisadores estrangeiros - ganharia ou perderia força explicativa? Ou, ainda, revelar-se-ia ele tão somente mais um elemento da ideologia administrativa?

Por fim, salientamos que, neste ensaio, não se objetivava fazer uma discussão exaustiva sobre o tema, apenas apresentá-lo enquanto possibilidade de introdução na agenda brasileira sem que esta fosse uma introdução domesticada. E, para isso, algumas ponderações foram realizadas e alguns questionamentos que surgiram das mesmas ficaram em suspenso, com a intenção de fomentar a discussão.

\section{Referências}

ACADEMY OF MANAGEMENT JOURNAL. Best Article Award for 2011. Academy of Management Journal, v. 55, n. 5, 2012.

ALVES, G. O novo (e precário) mundo do trabalho: reestruturação produtiva e crise do sindicalismo. São Paulo: Boitempo, 2005.

ANTUNES, R. Os sentidos do trabalho: ensaio sobre a afirmação e negação do trabalho. São Paulo: Boitempo, 1999.

ARGYRIS, C; SCHON, D. Organizational Learning. Reading, MA: Addison-Wesley, 1978. 
BASTOS, A. V. B.; GONDIM, S. M. G.; LOIOLA, E. Aprendizagem organizacional versus organizações que aprendem: características e desafios que cercam essas duas abordagens de pesquisa. Revista de Administração, São Paulo, v. 39, n. 3, p. 220-230, jul./ago./set. 2004.

BEER, M. The transformation of the Human Resource function: resolving the tension between a traditional administrative and a new strategic role. Human Resource Management, v. 36, n. 1, p. 49-56, Spring 1997.

BERNARDES, A. G.; GUARESCHI, N. M. F. Trabalhadores da saúde mental: cuidados de si e formas de subjetivação. Psicologia USP, v. 15, n. 3, p. 81-101, 2004.

BLACKMAN, D.; SADLER-SMITH, E. The silent and the silenced in organizational knowing and learning. Management Learning, v. 40, n. 5, p. 569-585, 2009.

BOWEN, F; BLACKMON, K. Spirals of silence: the dynamic effects of diversity on organizational voice. Journal of Management Studies, v. 40, n. 6, p. 1393-1417, 2003.

BROWN, A. D.; COUPLAND, C. Sounds of silence: graduate trainees, hegemony and resistence. Organization Studies, v. 26, n. 7, p. 1049-1069, 2005.

BRESSER-PEREIRA, L. C.; PRESTES MOTTA, F. C. Introdução à Organização Burocrática. 5. ed. São Paulo: Brasiliense, 1986.

BRINSFIELD, C. T.; EDWARDS, M. S.; GREENBERG, J. Voice and Silence in Organizations: historical review and current conceptualizations. In: GREENBERG, J.; EDWARDS, M. S. (Eds.). Voice and Silence in Organizations. Bingley, UK: Emerald Group Publishing Ltd., 2009, 3-33 p.

BUORO, G. O processo de compartilhamento do conhecimento: estudo de caso Tenarisconfab. 262 f. Dissertação (Mestrado em Administração) - Universidade de São Paulo, Faculdade de Economia, Administração e Contabilidade, São Paulo. 2005.

CARRIERI, A. P.; SILVA, A. R. L.; PIMENTEL, T. D. O tema da proteção ambiental incorporado nos discursos da responsabilidade social corporativa. Revista de Administração Contemporânea, Curitiba, v. 13, n. 1, p. 1-16, jan./mar. 2009.

CHAMBERLAIN, D. C. A. Terceirização e o Direito Trabalhista Brasileiro: as contradições econômicas, jurídicas e ideológicas. 119 f. Dissertação (Mestrado em Organizações e Desenvolvimento) - Centro Universitário Franciscano do Paraná, Programa de Mestrado em Organizações e Desenvolvimento, Curitiba. 2012.

CHANLAT, J. -F. Quais carreiras e para qual sociedade? (II). São Paulo, Revista de Administração de Empresas, v. 36, n. 1, p. 13-20, jan./mar. 1996.

DETERT, J. R.; EDMONDSON, A. C. Implicit voice theories: taken-for-granted rules of self-censorship at work. Academy of Management Journal, v. 54, n. 3, p. 461-488, 2011.

DUTTON, J. E.; ASHFORD, S. J. Selling issues to top management. The Academy of Management Review, v. 18, n. 3, p. 397-428, jul. 1993.

FARIA, J. H. Economia política do poder: crítica da teoria geral da administração. Curitiba: Juruá, 2004. v. 2.

FARIA, J. H.; MENEGHETTI, F. K. Burocracia como organização, poder e controle. Revista de Administração de Empresas, São Paulo, v. 51, n. 5, p. 424-39, set./out. 2011.

FERRAZ, D. L. S. Desemprego, exército de reserva, mercado formal-informal: rediscutindo categorias. 275 f. Tese (Doutorado em Administração) - Universidade Federal do Rio Grande do Sul, Programa de Pós-Graduação em Administração, Porto Alegre. 2010. 
FLANNERY, T. P.; HOFRICHTER, D.; FLATTEN, P. E. Pessoas, desempenho e salários: as mudanças na forma de remuneração das empresas. São Paulo: Futura, 1997.

FREITAS, M. E. Assédio moral e sexual: faces do poder perverso nas organizações. Revista de Administração de Empresas, São Paulo, v. 41, n. 2, p. 8-19, abr./jun. 2001.

HIRSCHMAN, A. O. Saída, voz e lealdade: reações ao declínio de firmas, organizações e estados. São Paulo: Perspectiva, 1973.

IASI, M. L. As metamorfoses da consciência de classe: o PT entre a negação e o consentimento. São Paulo: Expressão Popular, 2006

LEYVA-MORAL, J. M. Silencio organizacional: revisión bibliográfica de las razones y consecuencias del silencio en el trabajo. Index de Enfermería, Granada, v. 16, n. 57, sept. 2007, Disponível em: <http://scielo.isciii.es/scielo.php?pid=S1132-12962007000200007\&script=sci_arttext>. Acesso em: 23 de maio de 2013.

MAIA, T. S. T.; MAIA, F. S. Voz e silêncio: manifestações de resistência à mudança organizacional. In: Congresso Virtual Brasileiro de Administração, 5, 2008. Anais... Disponível em: <www.convibra.com.br/2008/artigos/256_0.pdf>. Acesso em: 28 de julho de 2013.

MILLIKEN, F. J.; MORRISON, E. W. Shades of silence: emerging themes and future directions for research on silence in organizations. Journal of Management Studies, v. 40, n. 6, p. 1563-68, 2003.

MILLIKEN, F. J.; MORRISON, E.; HEWLIN, P.F. An exploratory study of employee silence: issues that employees don't communicate upward and why. Journal of Management Studies, v. 40, n. 6, p. 1453-76, 2003.

MORRISON, E. W; MILLIKEN, F. J. Organizational silence: a barrier to change and development in a pluralistic world. Academy of Management Review, v. 25, n. 4, p. 706-25, 2000.

MORRISON, E. W; MILLIKEN, F. J. Speaking up, remaining silent: the dynamics of voice and silence in organizations. Journal of Management Studies, v. 40, n. 6, p. 1353-58, 2003.

OLTRAMARI, A. P. Dilemas relativos à carreira no contexto do trabalho imaterial bancário e suas repercussões nas relações familiares. $157 \mathrm{f}$. Tese (Doutorado em Administração) - Universidade Federal do Rio Grande do Sul, Programa de Pós-Graduação em Administração, Porto Alegre. 2010.

ORLANDI, E. P. As formas do silêncio: no movimento dos sentidos. 6. ed. Campinas, SP: Editora UNICAMP, 2007.

PAES DE PAULA, A. P. Tragtenberg revisitado: as inexoráveis harmonias administrativas e a burocracia flexível. Rev. Adm. Pública, Rio de Janeiro, v. 36, n. 1, p. 127-44, jan./fev. 2002.

PAIVA, K. C. M.; CASALECHI, T. T. Relações de Poder, assédio moral e burnout: um estudo numa escola particular de Belo Horizonte. In: HELAL, D. H; GARCIA, F.C; HONORIO, L. C. (Orgs.). Relações de Poder e de Trabalho no Brasil Contemporâneo. Curitiba: Juruá, 2010.

PERLOW, L.; WILLIAMS, S. Is silence killing your company? Harvard Business Review, v. 81, n. 5, p. 52-58, May 2003.

PINDER, C. C.; HARLOS, K. P. Employee silence: quiescence and acquiescence as responses to perceived injustice. Research in Personnel and Human Resource Management, v. 20, p. 331-69, 2001.

PREMAUX, S. F.; BEDEIAN, A. G. Breaking the silence: the moderating effects of self-monitoring in predicting speaking up in the workplace. Journal of Management Studies, v. 40, n. 6, p. 1538-62, 2003. 
PRESTES MOTTA, F. C. O poder disciplinar nas organizações formais. Revista de Administração de Empresas, São Paulo, v. 21, n. 4, p. 33-41, out./dez. 1981.

ROSEN, S.; TESSER, A. On reluctance to communicate undesirable information: the MUM Effect. Sociometry, v. 33, n. 3, p. 253-63, sep. 1970 .

SCHILLING, J.; KLUGE, A. Barriers to organizational learning: an integration of theory and research. International Journal of Management Reviews, v. 11, n. 3, p. 337-60, 2009.

SOBRAL, F.; MANSUR, J. A. Produção brasileira em comportamento organizacional no período 2000-2010. Revista de Administração de Empresas, São Paulo, v. 53, n. 1, p. 21-34, jan./fev. 2013.

TANGIRALA, S.; RAMANUJAM, R. Employee silence on critical work issues: the cross level effects of procedural justice climate. Personnel Psychology, v. 61, n. 1, p. 37-68, 2008.

TEO, H.; CASPERSZ, D. Dissenting discourse: exploring alternatives to the whistleblowing/silence dichotomy. Journal of Business Ethics, v. 104, n. 2, p. 237-249, 2011.

TONELLI, M. J. Sentidos do tempo e do tempo de trabalho na vida cotidiana. Organizações e Sociedade, Salvador, v. 15, n. 45, p. 207-217, abr./jun. 2008.

TRAGTEnBERG, M. A Teoria Geral da Administração é uma Ideologia? Revista de Administração de Empresas, São Paulo, v. 11, n. 4, p. 7-21, 1971.

TRAGtenBerg, M. Administração, Poder e Ideologia. São Paulo: Editora Unesp, 2005.

VAKOLA, M.; BOURADAS, D. Antecedents and consequences of organisational silence: an empirical investigation. Employee Relations, v. 27, n. 5, p. 441-58, 2005.

VASCONCELOS, I.; PRESTES MOTTA, F. C.; PINOCHET, L. H. C. Tecnologia, Paradoxos Organizacionais e Gestão de Pessoas. Revista de Administração de Empresas, São Paulo, v. 43, n. 2, p. 94-106, abr./maio/jun. 2003.

VAN DYNE, L.; ANG, S.; BOTERO, I. C. Conceptualizing employee silence and employee voice as multidimensional constructs. Journal of Management Studies, v. 40, n. 6, p. 1359-92, 2003.

VIEIRA, F. G. D. et al. Silêncio e omissão: aspectos da cultura brasileira nas organizações. RAE eletrônica, v. 1, n. 1, p. 1-11, jan./jun. 2002, Disponível em <http://goo.gl/3SDFI>. Acesso em 10 de maio de 2013.

WANG, Y. -D.; HSIEH, H. -H. Organizational ethical climate, perceived organizational support, and employee silence: a cross-level investigation. Human Relations, v. 66, n. 6, p. 783-802, 2013. 